\title{
O DIREITO AO LAZER E AS NOVAS EXPRESSÕES DA “QUESTÃO SOCIAL” FRENTE À (IR)REALIDADE BRASILEIRA
}

Recebidoem: 03/12/2012

Aceito em: 15/05/2013

\author{
Pedro Fernando Avalone Athayde ${ }^{1}$ \\ Universidade de Brasília \\ Brasília - DF - Brasil
}

RESUMO: Este artigo é resultado dos estudos e debates da disciplina "Questão Social, Instituições e Serviço Social”, do programa de pós-graduação em Política Social da Universidade de Brasília. O trabalho almeja relacionar o lazer como direito social às novas expressões da "questão social", considerando as especificidades da realidade nacional, sobretudo aquelas referentes às questões de gênero e étnico-raciais. $\mathrm{O}$ delineamento metodológico foi composto por pesquisa bibliográfica e documental, priorizando as referências utilizadas durante a disciplina. A análise epistemológica demonstrou falta de coesão sobre a gênese e natureza da "questão social". Posteriormente, verificamos que as mudanças societárias contemporâneas e as novas determinações da "questão social" engendram desigualdades de gênero e raciais no âmbito da sociedade brasileira, além de limitar o acesso ao lazer como direito social.

PALAVRAS-CHAVE: Atividades de Lazer. Política Social. Justiça Social.

\section{THE RIGHT TO LEISURE AND THE NEW EXPRESSIONS OF THE "SOCIAL ISSUE" IN THE BRAZILIAN (UN)REALITY}

ABSTRACT: This article is a result of the studies and debates carried out in the subject called "Social Issues, Institutions and Social Services", from the Social Policy postgraduate program, at the University of Brasilia. This paper aims to relate leisure as a social right to the new expressions of "social issues", considering the specificities of our national reality, mainly those related to gender and ethnic-racial issues. The methodology consisted of bibliographic and documental research, prioritizing the references used during the course. The epistemological analysis showed lack of cohesion between the genesis and the nature of the "social issue". After that, we verified that contemporary social changes and new "social issue" determinations entail gender and racial inequalities in the Brazilian society, and they also limit the access to leisure as a social right.

\footnotetext{
Mestre em Educação Física pela Universidade de Brasília. Doutorando do Programa de Pós-Graduação em Política Social da Universidade de Brasília. Membro do grupo de Pesquisa e Formação Sociocrítica em Educação Física, Esporte e Lazer - AVANTE da Faculdade de Educação Física da UnB.
} 
KEYWORDS: Leisure Activities. Public Policy. Social Justice.

\section{Introdução}

A sociedade atual representa um quadro que invejaria aos mais talentosos pintores abstracionistas. Vivemos num cenário onde o contraditório se expressa com grande vigor e intensidade. Somos a sociedade dos avanços científicos e tecnológicos inimagináveis e o local de uma acentuada e desumana desigualdade social.

Na sociedade capitalista, a incoerência e o ecletismo perderam sua fisionomia incômoda e conflituosa para, deliberadamente, assumirem o status de caminhos necessários a uma compreensão rica e coerente dos aspectos e fenômenos sociais. Dentro desse contexto, propagam-se e celebram-se as leituras pós-modernas do mundo, com sua superficialidade metafísica. Ao mesmo tempo, banalizam-se e naturalizam-se os problemas sociais.

Como não ter aversão por uma sociedade que mantém níveis de pobrezas inaceitáveis, embora detenha os atributos e condições necessários para sua extirpação? Segundo Mishra (1975), no âmago da sociedade capitalista está o paradoxo do crescimento das necessidades e a maneira de satisfazê-las. Essa explícita e inóspita discrepância veio à tona no final do século XVIII com o fenômeno do pauperismo, situação inédita na qual a condição de pobreza crescia em patamares alarmantes, que obstaculizavam a reprodução da força de trabalho.

De acordo com Netto (2001), o pauperismo é o responsável pelo surgimento da expressão “questão social"”. Quanto a essa denominação, é importante destacar alerta do

\footnotetext{
$\overline{{ }^{2} \text { Utilizaremos neste texto as aspas }}$ para o termo "Questão Social", por compartilhamos da conclusão proferida pelo professor José Paulo Netto de que a referida expressão trata-se de uma tergiversação conservadora, colada a sociedade burguesa.
} 
autor de que “[...] a expressão 'questão social' não é semanticamente unívoca; ao contrário, registram-se em torno dela compreensões diferenciadas e atribuições de sentido muito diversas" (NETTO, 2001, p. 41).

Netto (2001) afirma que, não obstante as desigualdades entre as diferentes camadas sociais e a distinta capacidade de apropriação e fruição de bens entre pobres e ricos existirem a muito tempo, a dinâmica de pobreza engendrada pelo pauperismo era radicalmente nova.

\begin{abstract}
Pela primeira vez na história registrada, a pobreza crescia na razão direta em que aumentava a capacidade social de produzir riquezas. Tanto mais a sociedade se revelava capaz de progressivamente produzir mais bens e serviços, tanto mais aumentava o contingente de seus membros que, além de não ter acesso efetivo a tais bens e serviços, viam-se despossuídos das condições materiais de vida que dispunham anteriormente (NETTO, 2001, p. 42 e 43).
\end{abstract}

Esse cenário no qual o "remédio" tem caráter venéfico, uma vez que a riqueza e pobreza se hipertrofiam em proporção semelhante a que se distanciam, tem sido intensificado ao longo dos anos com a sobrevivência e reestruturação do sistema capitalista. Essa constatação nos permite ratificar a premência da "questão social" na atualidade.

Diante da presença de contornos contemporâneos, autores (CASTEL, 2009; ROSANVALLON, 1998) identificaram a gênese de uma "nova questão social". O debate acerca das expressões modernas da "questão social" permitiu o surgimento de

discussões ligadas a grupos e direitos sociais, que histórica e tradicionalmente foram ignorados. Dentre esses direitos subjugados, destacaremos neste texto o Lazer, localizando e analisando-o no âmbito dessas possíveis novas determinações da "questão social". 
Sem embargo do debate prévio sobre a existência ou não de uma "nova questão social”, almejamos contextualizar, numa dimensão sócio histórica, a origem do lazer e sua vinculação aos direitos sociais. Ao mesmo tempo, tentaremos construir reflexões sobre as possíveis imbricações do lazer às novas expressões da "questão social". Ademais, cotejaremos nossa análise com algumas singularidades presentes na desigual realidade brasileira contemporânea.

Para consecução desses objetivos, realizamos pesquisa bibliográfica e documental composta basicamente de textos utilizados e debatidos durante a disciplina “Questão Social, Instituições e Serviço Social”, ministrada no Programa de PósGraduação em Política Social da Universidade de Brasília. Complementarmente, utilizamos algumas fontes que nos permitiram o diálogo mais próximo com as especificidades e particularidades de nosso objeto central de investigação.

\section{De que “questão social" estamos falando...}

O debate em si sobre a gênese do termo "questão social" demonstra toda a pujante desarmonia acerca da possibilidade de uma compreensão unificada do que ela venha ser. Uma parcela dos pesquisadores e professores vinculados direta e indiretamente ao Serviço Social - amparados por estudos vinculados à tradição marxista - afirma que o aparecimento da "questão social" é historicamente datado como produto da ordem capitalista. De acordo com esse grupo, a referida constatação é permitida pela análise marxista do caráter exploratório do sistema capitalista, que demonstra com clareza a distinção entre a "questão social" e as expressões sociais derivadas da escassez em sociedades antecessoras ao capitalismo.

Segundo Netto (2001, p. 42): 
Todas as indicações disponíveis sugerem que a expressão "questão social" tem história recente: seu emprego data de cerca de cento e setenta anos. Parece que começou a ser utilizada na terceira década do século XIX e foi divulgada até a metade daquela centúria por críticos da sociedade e filantropos situados nos mais variados espaços do espectro político.

Corroborando com o autor, Pereira (2001) é incisiva ao asseverar que não existe uma questão social antes da Revolução Industrial. A afirmação da autora está alicerçada na certeza de que foram - em sua opinião - as mudanças das relações sociais de produção decorrentes daquele momento histórico as responsáveis pela criação de duas classes diametralmente opostas: a burguesia e oproletariado.

Iamamoto (2001), também, reforça a importância da historicidade para a análise da "questão social", destacando a necessidade de consideração da relação entre essa e as configurações assumidas pelo trabalho. Ao debater tal vinculação, afirma que a "questão social” é consequência do processo de lutas sociais da classe operária.

É fato conhecido que historicamente a questão social tem a ver com a emergência da classe operária e seu ingresso no cenário político, por meio das lutas desencadeadas em prol dos direitos atinentes ao trabalho, exigindo o seu reconhecimento como classe do bloco do poder, e, em especial pelo Estado. Foram as lutas sociais que romperam o domínio privado nas relações entre capital e trabalho, extrapolando a questão social para a esfera pública, exigindo a interferência do Estado para o reconhecimento e a legalização de direitos e deveres dos sujeitos sociais envolvidos (IAMAMOTO, 2001, p.17).

Diferentemente dos autores acima, outros estudiosos do tema assumiram o entendimento de que a "questão social” não é um fenômeno historicamente determinado e que, portanto, não estaria diretamente vinculado à formação social capitalista ou à própria Revolução Industrial. Entre os que compartilham dessa compreensão, ressaltamos os estudos de Robert Castel (2009), para quem:

A "questão social" é uma aporia fundamental sobre a qual uma sociedade experimenta o enigma de sua coesão e tenta conjurar o risco de sua fratura. É um desafio que interroga, põe em questão a capacidade de uma sociedade (o que, em termos políticos, se chama uma nação) para existir como um conjunto ligado por relações e interdependência (CASTEL, 2009, p. 30). 
Castel (2009) reconhece que a determinação conceitual da "questão social” é consequência da tomada de consciência das condições de existência das populações que são, simultaneamente, os protagonistas e as vítimas da Revolução Industrial. Além disso, admite a importância do pauperismo para a clarividência dada à "questão social" nesse período. Entretanto, problematiza o que denomina de "invenção do social" ponderando sobre a existência de um conteúdo social em sociedades pretéritas à organização europeia pós-industrial.

De acordo com o autor, os modos sistemáticos de intervenção em relação a algumas populações (repressão da vagabundagem; obrigação do trabalho; controle da circulação da mão de obra) e as intervenções públicas por meio das quais o Estado desempenha seu papel de fiador da manutenção da organização do trabalho e de regulador da mobilidade dos trabalhadores explicitam a presença de uma "questão social" em sociedades pré-capitalistas.

Castel (2009) também promove um debate controverso sobre a ideia de uma “nova questão social”. Outro autor que compartilha dessa hipótese é Pierre Rosanvallon. Embora possuam algumas particularidades, ambos defendem, em síntese, a presença de uma nova configuração da questão social engendrada pelas recentes transformações nas condições de trabalho.

Para Castel (2009), há, atualmente, uma condição de precarização do trabalho composta por um conjunto de fatores, tais como: a) a acentuada flexibilização do trabalho; b) a degradação da condição salarial; c) a ausência de uma relação direta entre aumento da qualificação e empregabilidade; d) a desestabilização dos estáveis; e) a

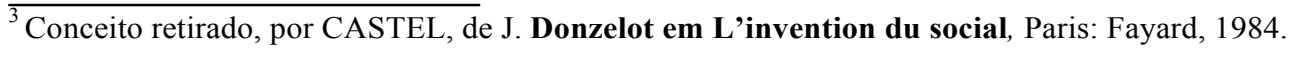


instalação na precariedade; e f) a manifestação de um déficit de lugares. Dentro dessa perspectiva, o autor afirma que a atual precarização do trabalho, promovida pelas novas exigências tecnológicas e econômicas da evolução do capitalismo moderno, tornou-se um elemento tão fundamental para a constituição de uma "nova questão social" quanto o pauperismo durante a Revolução Industrial.

Pereira, Netto e Iamamoto (2001) refutam a ideia de uma "nova questão social". Para Pereira (2001), mesmo que na atualidade tenhamos uma classe trabalhadora minada pela pluralidade de interesses e que a influência cultural do pensamento de esquerda esteja debilitada, o que está na estrutura desses problemas é o secular confronto entre as forças produtivas e as relações de produção, que é o provedor da desigualdade social e base da "questão social".

Netto (2001) concorda com a autora sobre a inexistência de uma "nova questão social". Segundo o autor, o que temos contemporaneamente é a emergência de novas expressões da "questão social”, que são insuperáveis sem a supressão da ordem capitalista.

A dinâmica específica dessa ordem [capitalista] não só põe e repõe os corolários da exploração que a constitui medularmente: a cada novo estágio de seu desenvolvimento, ela instaura expressões sócio humanas diferenciadas e mais complexas, correspondentes à intensificação da exploração que é a sua razão de ser (NETTO, 2001, p.48).

Leitura semelhante realiza Iamamoto (2001) ao ratificar o pensamento sobre a existência de "novas determinações históricas da questão social", complexificadas na sua forma de expressão, ao mesmo tempo, em que se radicaliza, espraiando-se sobre as mais distintas dimensões da vida das classes subalternas.

Em que pese a provável superficialidade que dedicamos ao tratamento de um debate tão relevante, entendemos que é importante evidenciar nosso acordo com os 
autores que realizam uma análise centrada nos elementos históricos e estruturais da “questão social” e que, deste modo, contestam a aplicabilidade de suas adjetivações (antiga e nova). Compreendemos que, a despeito da relevância e influência das transformações contemporâneas, os axiomas e as antinomias basilares do capitalismo persistem. Entretanto, a adoção desse entendimento requer que estejamos atentos ao alerta realizado por Netto $(2001$, p. 49), qual seja: “[...] a caracterização da 'questão social', em suas manifestações já conhecidas e em suas expressões novas, tem de considerar as particularidades histórico-culturais e nacionais".

\section{O Lazer como direito social}

Historicamente, o lazer ${ }^{4}$ ocupou - e ainda ocupa - papel coadjuvante no conjunto dos direitos sociais. Se solicitássemos às pessoas que, aleatoriamente, citassem quais são os direitos sociais, provavelmente, a maior parcela dos entrevistados não mencionaria o lazer, denotando que uma grande parcela da sociedade não o reconhece como direito.

A localização do lazer como um direito de segunda ordem ou de menor relevância é fruto de uma série de fatores, dentre os quais, a omissão estatal. Normalmente, motivados por diferentes aspectos, os governos - independentemente da filiação partidária e da orientação ideopolítica - têm predileção por determinados setores

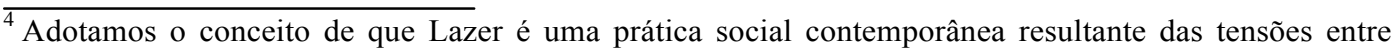
capital e trabalho, que se materializa como um tempo e espaço de vivências lúdicas, lugar de organização da cultura, perpassado por relações de hegemonia (MASCARENHAS, 2005).
} 
imprescindíveis à harmonia do funcionamento global da máquina governamental. Essa preferência se evidencia na hegemonia da política macroeconômica - sobretudo nas pautas que favorecem o capital financeiro - sobre a área social. Mesmo no rol dos direitos sociais, o lazer e a cultura são preteridos - especialmente no campo discursivo em relação à saúde, educação e segurança, temas recorrentes nas campanhas eleitorais e nas peças publicitárias dos governos eleitos.

Dados do Orçamento Fiscal e da Seguridade Social de 2012, excluindo o refinanciamento da Dívida Pública, apontam a destinação de $\mathrm{R} \$ 1,6$ bilhão para atendimento ao esporte e lazer e a mesma quantia para à cultura. Para a saúde, educação e segurança pública foram repassados, respectivamente, $\mathrm{R} \$ 79,5 ; 66,5$ e 8,4 bilhões. Entretanto, a eminente supremacia do capital especulativo é confirmada quando verificamos que para amortização e pagamento dos juros da dívida pública foram destinados 361,5 bilhões de reais.

Essa opção ou estratégia governista perpetua os atrasos existentes nos setores com menor capacidade de provocar riscos à governabilidade e de tencionar o ordenamento social hegemonizado por determinadas frações da burguesia. Nesse caso, “os setores da vida social que se encontram em crise, mas que não se caracterizam como ameaça ao sistema, são relegados à periferia da ação do Estado, mediante intervenções mínimas, que objetivam apenas evitar o acirramento de tensões” (LINHALES, 1996, p. 48). Pressupomos que esse seja o caso dos agrupamentos sociais que militam em defesa da garantia do aceso ao lazer e a cultura como direitos sociais.

O artigo XXIV, da Declaração Universal dos Direitos Humanos de 1948, antecipa que: "toda pessoa tem direito a repouso e lazer, inclusive a limitação razoável das horas de trabalho e férias periódicas remuneradas". Além disso, o lazer localiza-se 
entre os direitos sociais ${ }^{5}$ explicitados pelo artigo $6^{\circ}$, da Constituição Federal $(C F)$ de

1988 e compõe as necessidades vitais básicas que devem ser atendidas pelo saláriomínimo ${ }^{6}$, conforme o próprio texto constitucional.

Para além da relevância e reconhecimento consignados no aparato jurídico-legal, é importante destacarmos que o lazer é um fenômeno cultural que possui vínculos com as lutas operárias pela redução da jornada de trabalho e pela conquista do tempo-livre. Essa junção demonstra toda sua importância histórica, política e social deste fenômeno, situando-o no contexto histórico de surgimento da "questão social".

A denúncia de Marx (1988) acerca da exploração capitalista em busca do prolongamento da jornada de trabalho até o limite máximo deixava evidente a importância do tempo-livre para a reprodução social da classe trabalhadora, inclusive para usufruto do lazer.

É por certo muito lamentável que qualquer classe de pessoas seja obrigada a se esfalfar 12 horas diariamente. Adicionando-se as horas das refeições e para ir e voltar da fábrica, elas totalizam, de fato, 14 das 24 horas do dia. [...] Abstraindo a saúde, ninguém hesitará, espero, em admitir que do ponto de vista moral essa absorção completa do tempo das classes trabalhadoras, sem interrupções, desde a idade dos 13 anos e desde muito antes, nos ramos industriais "livres" é extremamente nefasta e um mal terrível. [...] No interesse da moral pública, para a formação de uma população apta e a fím de proporcionar à grande massa do povo razoável gozo da vida, é necessário que em todos os ramos de atividade seja reservada uma parte de cada dia de trabalho para descanso e lazer (HORNER, 1841, apud MARX, 1988, p. 391).

\footnotetext{
${ }^{5}$ Vale destacar que compartilhamos da compreensão de Pereira (2008) sobre os direitos sociais, ou seja, de que: [...] referenciados no princípio da igualdade, tendo como responsável o Estado de Bem-Estar. Esses direitos, porém, não se coadunam com o ideário liberal e, por isso, requerem reformulações desse ideário e de suas práticas, no próprio seio do capitalismo. Tal dissonância reside no fato de tais direitos não se colocarem contra o Estado, mas, diferentemente dos direitos individuais, exigirem a participação cívica deste na vida da sociedade. Com a existência dos direitos sociais houve também mudança de acento no princípio da liberdade para o princípio da igualdade (PEREIRA, 2008, p. 105).

${ }^{6}$ Em relação ao salário-mínimo é instigante notarmos a gritante diferença ente o salário-mínimo nominal (salário-mínimo vigente) pago aos trabalhadores que, recentemente, foi reajustado para $\mathrm{R} \$ 545,00$ e o salário-mínimo necessário calculado pelo Departamento Intersindical de Estatística e Estudos Socioeconômicos - DIEESE, que leva em consideração o preceito constitucional e que em dezembro de 2010 era de $\mathrm{R} \$ 2.227,53$.
} 
Por conseguinte, percebemos uma evidente relação entre lazer e trabalho. Todavia, é intrigante notarmos que esses dois fenômenos ganham percepções e/ou interpretações axiológicas antagônicas perante a sociedade. O lazer é comumente vinculado a aspectos positivos de fruição, ludicidade e prazer, ao passo que o trabalho é diretamente relacionado ao seu caráter extenuante fruto das longas jornadas de trabalho, à produtividade, à seriedade e rigidez.

O trabalho se apresenta como tamanha desrealização que o indivíduo só se sente "livre" quando está fora dessa atividade. Liberado de sua atividade produtiva obrigatória, o indivíduo preenche o seu tempo fora do trabalho com inúmeras outras atividades, entre elas com o lazer. Assim, lazer e trabalho aparecem, a uma primeira vista, como fenômenos absolutamente distintos aos olhos dos indivíduos e a vida no trabalho é tamanhamente sem sentido que o trabalhador, uma vez livre dela, procura ocupar o seu tempo com atividades que o façam esquecer do trabalho. Seria como se o trabalho fosse a doença e o lazer o seu remédio (HÚNGARO, 2008, p. 229).

O referido autor alerta-nos para o conteúdo alienante que permeia essa naturalização da oposição entre esses fenômenos, ofuscando o trabalho como momento ontologicamente determinante do lazer. Em verdade, no interior da ordem capitalista, verificamos que o lazer apresenta-se primordialmente como uma estratégia de controle do capital sobre o tempo livre da classe trabalhadora ou como uma mercadoria com elevado potencial de venda. Condição que está diretamente relacionada com a transição descrita por Bauman (2010, p. 15), onde assistimos "a passagem de uma sociedade de produtores para uma sociedade de consumidores". Transição que, conforme alerta Mészáros (2009), acentua a importância da figura do trabalhador como consumidor dentro da produção capitalista, ainda que este se veja excluído do controle tanto da produção, quanto da distribuição.

Atualmente, o capital espraia seu domínio para a totalidade da vida humana, mercantilizando todos os fenômenos sociais. De acordo com Netto (1996, p. 97), a 
dinâmica cultural de nossa época está fundada em dois vetores: “[...] a translação da lógica do capital para todos os processos do espaço cultural (produção, divulgação e consumo) e desenvolvimento de formas culturais socializáveis pelos meios eletrônicos (a televisão, o vídeo, a chamada multimídia)". Dentro desse contexto, o tempo livre e o lazer são, igualmente, tragados pela lógica do capital.

O potencial mercadológico do lazer é reafirmado, constantemente, pelas vultosas cifras movimentadas pela indústria do entretenimento, segmento hegemônico do lazer contemporâneo. Segundo projeções da página propmark, do sítio UOL, a indústria de entretenimento e mídia deve gerar, mundialmente, US\$ 2,1 trilhões em 2016, com expansão anual de 5,7\%. Em 2011, o volume foi de US\$1,6 trilhão ${ }^{7}$

Considerando nosso pressuposto de que o debate sobre o lazer como direito social relaciona-se aos impactos das mutações do mundo do trabalho sobre as expressões e determinações contemporâneas da "questão social”, faz-se imprescindível averiguarmos de que maneira o tempo livre e o direito ao lazer são afetados por essas transformações.

\section{Relações entre o lazer e as expressões contemporâneas da "questão social”}

Nesta parte do texto, almejamos identificar as implicações das novas expressões da “questão social” sobre o lazer como direito social e, portanto, como objeto de atenção da política social. Contudo, não realizaremos esse percurso sem nos recordarmos da

\footnotetext{
${ }^{7}$ Dados da matéria "Brasil se tornará o $7^{\circ}$ maior mercado de mídia e entretenimento em 2016". Disponível em: http://propmark.uol.com.br/agencias/40832:brasil-se-tornara-o-7-maior-mercado-demidia-e-entretenimento-em-2016. Acesso em: 1 abr. 2013.
} 
prudente consideração de Netto (2001), ou seja, de que devemos contemplar nessa análise as especificidades sociais, históricas e culturais do Brasil.

Nesse sentido, a despeito de rejeitarmos a eminência de uma "nova questão social", consideraremos a interferência dos aspectos culturais sobre a totalidade analisada, bem como as mudanças que dizem respeito, mais especificamente, ao objeto de análise adotado e ao contexto social observado. Em outras palavras, apreciaremos mesmo que sucintamente - as transformações inerentes ao lazer contemporâneo, bem como as disfunções (políticas, sociais e culturais) endógenas à organização da sociedade brasileira, com acento nas questões de gênero e étnico-raciais.

Segundo Telles (1999), as especificidades da sociedade brasileira dramatizam a questão social, sobretudo em um país cujas transformações e modernizações se processam em ritmo avassalador, contudo, sem o acompanhamento da garantia dos princípios básicos da igualdade civil e patamares mínimos de igualdade social. Quadro que se agrava diante de um país marcado por enormes disparidades, em que as carências sociais são tão grandes quanto diferenciadas, conforme regiões e grupos afetados e no qual parcelas ponderáveis da população estão à margem das arenas organizadas do conflito. De acordo com Telles (1999), o Brasilapresenta:

[...] uma sociedade atravessada por conflitos específicos e demandas nãogeneralizáveis e um ordem legal também ela assimétrica na garantia de direitos e prerrogativas, configura-se uma dinâmica política que carrega o risco de produzir uma geometria variável de direitos conforme as diferenças no poder de negociação dos grupos envolvidos (TELLES, 1999, p. 149).

Sem incorrer numa displicência redundante ou incoerente, é possível afirmarmos que o capitalismo contemporâneo é, ao mesmo tempo, igual e diferente àquele do início do processo de industrialização. Uma grande parte dos problemas advindos da gênese do sistema de capital se perpetua, ao mesmo tempo em que novos obstáculos são 
criados. Pereira (2001) oferece-nos um conjunto de problemas de ordem planetária e que se difundem sem grandes contestações sociais. Dentre eles, a autora destaca: a) a ameaça bélica; b) a deterioração do meio ambiente; c) o aprofundamento da desigualdade social; $d$ ) a globalização da pobreza; e) o acirramento do racismo e das lutas étnicas; e f) o desmonte dos direitos sociais.

Os problemas citados se imiscuem às novas expressões da "questão social". No que tange a essas novas mediações históricas, Iamamoto (2001) apresenta quatro aspectos centrais com os quais concordamos, a despeito da necessidade de um novo exame a partir das modificações sociais mais recentes. Passemos à exposição e problematização desses aspectos.

O primeiro aspecto, destacado por Iamamoto (2001), fazer referência à dinâmica financeira do regime de acumulação que tende a provocar crises que são o corolário da recessão mundial. Essa lógica é pautada na noção de volatilidade do crescimento, que se reverte em maior concentração de renda e aumento da pobreza. Em virtude desse processo são favorecidos os investimentos especulativos em detrimento da produção, o que ocasiona a redução dos níveis de emprego, o agravamento da "questão social" e a regressão das políticas públicas sociais.

Esse panorama é comprovado pela organização econômica dos países, principalmente os classificados como periféricos. Ao olharmos para o caso brasileiro, observaremos que a referida perspectiva é comprovada pela subordinação da política econômica ao superávit primário; pelo crescimento desenfreado do setor terciário; pelo projeto de desenvolvimento econômico sustentado no aquecimento do consumo; e pelo modelo de gestão empresarial do Estado, que retrai e focaliza o investimento em políticas sociais. 
O segundo aspecto, apresentado por Iamamoto (2001), é a passagem do modelo fordista-taylorista de organização da produção para o de "acumulação flexível", arquétipo no qual a produção destina-se a mercados específicos, buscando atender variabilidades culturais e regionais e voltando-se para as peculiaridades de setores particulares de consumo. Baseada na ideia de redução de custo e aumento da lucratividade, a passagem à "flexibilidade" afeta os processos de trabalho, as formas de gestão da força de trabalho, o mercado de trabalho e os direitos sociais e trabalhistas. Ao mesmo tempo, a luta sindical é acometida por um quadro de recessão e desemprego. Esse cenário desalentador é engendrado pela restruturação produtiva, que intensifica a divisão social e técnica do trabalho e o avanço tecnológico, criando a figura mítica do trabalhador polivalente.

Atualmente, em razão da velocidade com que ocorrem os avanços tecnológicos e da robótica, surgem novas discussões acerca da dinâmica organizativa do trabalho. Todavia, no Brasil, para o debate dessas transformações, algumas questões devem ser consideradas, tais como: um grande contingente de trabalhadores informais; uma baixa taxa de escolaridade entre os trabalhadores, que coloca em xeque o discurso sobre polivalência e a especialização técnica do trabalhador; a reconfiguração da ação e do papel dos sindicatos nos últimos anos, inclusive vinculando-se organicamente à estrutura de governo.

As mudanças na relação entre Estado e sociedade civil, diante da lógica neoliberal, correspondem ao terceiro aspecto destacado pela autora. Tais alterações são marcadas pelo redirecionamento da intervenção estatal, guiado pelos interesses privados de inspiração neoliberal, na direção da redução do papel do Estado. Os resultados dessa 
escolha são a intensificação do processo de privatização da coisa pública, a desresponsabilização estatal e a apropriação privada do fundo público.

Segundo Behring (2009), guiado pela necessidade de favorecer as finanças e garantir elevados níveis de superávit primário, o Estado tem diminuído sua participação na realização de investimentos públicos e no oferecimento de políticas sociais públicas e/ou universais. Esse recuo ocorre a partir de duas vias: de um lado por meio da transferência de responsabilidades governamentais para as "organizações sociais" e “organizações da sociedade civil de interesse público”; de outro lado promove uma crescente mercantilização do atendimento às necessidades sociais, garantindo espaços para o capital privado na esfera da prestação de serviços sociais.

Se por um lado, é verdade que no Brasil - após 2003 - assistimos um acanhado arrefecimento das privatizações "diretas", sobretudo no âmbito federal, na comparação com gestões presidenciais anteriores. Uma redução que está diretamente ligada a dois fatores: sendo o primeiro deles o fato de que grande parte das empresas e companhias públicas estarem privatizada; e o segundo aspecto refere-se à reorganização do papel das estatais dentro da política econômica nacional, cujos exemplos marcantes são os investimentos realizados pela Petrobras e a ampliação do acesso ao crédito por meio dos bancos públicos (Banco do Brasil, CAIXA, Banco do Nordeste e BNDES).

Todavia, Boito Jr. (2006) destaca que o governo Lula manteve os contratos leoninos que asseguravam alta lucratividade aos novos monopólios privados e não se dispôs a investigar os casos de corrupção mais rumorosos que envolveram a política de privatização. Além disso, as modificações citadas acima, não impediram que, durante a gestão do governo Lula, ocorresse o que denominamos de privatização "indireta". Fenômeno que se materializa nos projetos encaminhados pelo governo Lula de Parceria 
Público-Privado (PPP) para serviços públicos e infraestrutura, assegurando em Lei a lucratividade dos grandes grupos econômicos, uma vez que está previsto no projeto das PPPs a suplementação de dinheiro público para os empreendimentos que não atingirem a lucratividade esperada.

Ademais, observamos o recrudescimento do enxugamento da ação estatal nos programas e projetos sociais por meio da transferência de responsabilidades ao "terceiro setor ${ }^{8} "$. O crescimento da participação do terceiro setor nas políticas públicas advém do questionamento à legitimidade da promoção de políticas sociais universais pelo Estado, sob o a alegação da existência de formas "mais democráticas" de enfrentamento da “questão social". Ao mesmo tempo, evoca-se o argumento da necessidade de adoção de um modelo de gestão mais eficiente e menos burocrático, o que seria inviável a partir da estrutura estatal.

Esse entendimento conduz os gestores públicos e a própria sociedade civil a uma compreensão ilusória, sumarizada pela seguinte linha de raciocínio: em lugar das organizações do Estado (burocrático e ineficiente) ou do mercado (lucrativo), as organizações da sociedade civil assumem a tarefa de dar respostas às demandas sociais,

trata-se de uma concepção claramente de inspiração liberal. Destarte, funda-se uma categoria (terceiro setor) que representa um cenário amigável e pacífico de convivência entre objetivos incompatíveis, imperceptível na realidade concreta. Essa construção

\footnotetext{
${ }^{8}$ Segundo Montaño (2002), o termo “terceiro setor" não é axiologicamente neutro, visto que possui uma procedência norte-americana e é engendrado dentro de um contexto no qual associativismo e voluntariado fazem parte de uma cultura política e cívica baseada no individualismo liberal.
} 
ficcional é funcional ao projeto neoliberal representa o sucesso da luta do capital por instrumentalizar a sociedade civil (MONTAÑO \& DURIGUETTO, 2010).

Vale ressaltar que a passagem das ações estatais ao terceiro setor é recorrente no âmbito das políticas públicas sociais de lazer ${ }^{9}$. No presente, é corriqueira a submissão da gestão de programas e projetos sociais de lazer às organizações não governamentais, com o suporte do financiamento público. No entanto, no momento em que as ONGs firmam parcerias com o Estado para desempenhar - de forma terceirizada - determinadas atribuições, comprometem seu caráter "não governamental" e de "autogovernação". Isso porque, a maioria dessas organizações - cônscia ou não - está fortemente condicionada pelo direcionamento e financiamento governamental. Ou seja, sua sobrevivência, bem como de seus projetos, está vinculada aos determinantes políticos e econômicos da agenda governamental, o que não significa a retomada da responsabilidade estatal.

O último elemento apresentado por Iamamoto (2001) mantém relação com as interferências sofridas pelas formas de sociabilidade. Para a autora, vivemos numa “sociedade do mercado" (LECHNER, 1999, apud IAMAMOTO, 2001), que se organiza a partir de uma lógica pragmática e produtivista. A implicação disso é a germinação de uma mentalidade utilitária e da naturalização da sociedade, ou seja, "é assim mesmo, não há como mudar”.

\footnotetext{
${ }^{9}$ Com o objetivo de apresentar um "retrato" sobre as instituições privadas sem fins lucrativos que atuam no Brasil, o Instituto Brasileiro de Geografia e Estatística - o IBGE -, o Instituto de Pesquisa Econômica Aplicada - o IPEA, a Associação Brasileira de Organizações Não-Governamentais - a ABONG e o Grupo de Institutos, Fundações e Empresas - GIFE realizaram, em 2002, um estudo intitulado "As Fundações Privadas e Associações Sem Fins Lucrativos no Brasil". Essa pesquisa foi reproduzida nos anos de 2006, 2008 e 2010. As organizações identificadas foram distribuídas em grupos e subgrupos, sendo que, em 2002, o grupo definido como "Cultura e recreação" contava com 37.539 organizações. Esse quantitativo se manteve ao longo dos anos com pequena redução - em 2010 existiam 36.921 organizações.
} 
Os quatro aspectos apresentados por Iamamoto (2001) referem-se, prioritariamente, as mutações do mundo do trabalho e ao processo de desenvolvimento da sociedade capitalista. Essas modificações afetam diretamente as esferas do Estado e do mercado. Entretanto, também, impactam - ao mesmo tempo em que são impactadas pelas modificações no padrão familiar tradicional.

$\mathrm{Na}$ atualidade, verificamos que as famílias têm apresentado características como:

i) maior instabilidade dos matrimônios, com aumento das taxas de divórcio e seguidas núpcias; ii) maior probabilidade de constituição de famílias monoparentais, com aumento da incidência de pobreza justamente nestes domicílios; iii) maior dificuldade de conciliação entre carreira profisssional e atividades domésticas, ou dito de outra forma, um trade off complicado entre optar pelo trabalho fora de casa (opção vinculada à taxa de participação) e a opção pela maternidade (opção vinculada à taxa de natalidade); iv) maior desigualdade de rendimentos entre tipos diferentes de composição familiar; v) maior insegurança pessoal decorrente os riscos sociais no âmbito das famílias, mas também decorrentes dos riscos presentes no mundo do trabalho, isto é; proliferação de contratos atípicos de trabalho (part time e tempo determinado), jornadas de trabalho e rendimentos instáveis e irregulares no tempo, aposentadorias e pensões de valores insuficientes ou incertos, maiores taxas de desemprego localizadas entre os jovens até 24 anos e as mulheres, desemprego de longa duração para adultos ainda na fase ativa da vida profissional (SEP, 2004, n.p.).

Ao relacionarmos as mudanças da composição familiar com aquelas referentes ao mundo do trabalho torna-se necessário debatermos a questão de gênero dentro desse contexto. Nossa assertiva decorre do fato de que as mulheres são as principais afetadas pelas novas configurações da família, uma vez que, dentro de uma sociedade fundada em padrões masculinos, compete a elas o cuidado familiar e as tarefas domésticas. Portanto, são as mulheres que ficam sujeitas às duplas jornadas de trabalho; à submissão a trabalhos em condições subalternizadas; ao trade off ${ }^{10}$; à aceitação de um padrão salarial reduzido em comparação aos homens.

\footnotetext{
${ }^{10}$ Condição de incompatibilidade entre o trabalho e o cuidado familiar vivenciada pelas mulheres.
} 
No Brasil, a condição das mulheres agrava-se, na medida em que elas compõem a maioria da mão-de-obra dentro de um mercado de trabalho caracterizado pelo alto índice de informalidade. Segundo Relatório da Comissão Externa da Feminização da Pobreza (2004), do Senado Federal, a proporção de mulheres que se encontra nas ocupações precárias (61\%) é 13\% superior à proporção de homens nessa mesma situação (54\%). Cabe destacar que, no caso das mulheres negras, essa extensão sobe para $71 \%$, sendo que $41 \%$ delas se concentram nas ocupações mais precárias e desprotegidas do mercado de trabalho.

Ademais, verificamos uma baixa cobertura do sistema de educação e cuidado de crianças pequenas, bem como, uma visão hegemônica da assistência social em relação ao lugar da mulher como cuidadora/beneficiária (GAMA, 2008). McIntosh ${ }^{11}$ (2000, apud GAMA, 2008) defende que a luta feminista deve buscar a conexão entre o âmbito da produção e da reprodução locais onde ocorre a exploração-dominação. A autora alerta para os riscos contidos no discurso do alcance da igualdade de gênero por meio do fortalecimento dos laços das mulheres com o trabalho, assim como, reforça a fragilidade na abordagem das políticas sociais. Nesse sentido, observamos que a superação das desigualdades engendradas pelo recorte de gênero passa pelo atendimento das reivindicações feministas junto ao Estado de Bem-Estar Social, ou seja, de uma total neutralidade de gênero na alocação de oportunidades, chances de vida e nos resultados do bem-estar.

Se a questão de gênero é de extrema relevância dada sua concreticidade na realidade brasileira, o mesmo se aplica às demandas raciais. Afinal, o Brasil é um país

\footnotetext{
${ }^{11}$ MCINTOSH, Mary.Feminism and Social Policy. Oxford (USA): Blackwell, 2000.
} 
com uma enorme dívida histórica e social com as comunidades afrodescendentes. Além disso, somos uma nação composta por uma maioria populacional negra, a qual não deve ser cerceada de sua prerrogativa de acesso aos direitos sociais.

A Declaração Universal dos Direitos Humanos (DUDH) afirma que:

Toda pessoa tem capacidade para gozar os direitos e as liberdades estabelecidos nesta Declaração, sem distinção de qualquer espécie, seja de raça, cor, sexo, língua, religião, opinião política ou de outra natureza, origem nacional ou social, riqueza, nascimento, ou qualquer outra condição (UNESCO, 1948, n.p.).

No Brasil, o princípio acima é, por vezes, ignorado, o que o coloca numa condição ainda distante de sua materialização. Na década de 50, com a divulgação da obra de Gilberto Freyre, disseminou-se no país a concepção de uma democracia racial, que reinventava a quimera de que no Brasil haveria uma boa convivência e paz social. Entretanto, essa perspectiva não implicava na integral negação do caráter irreversível da inferioridade dos negros (JACCOUD, 2008).

A noção de democracia racial foi devidamente criticada e refutada com estudos que demonstravam a perpetuação da desigualdade e descriminação no Brasil. Segundo Jaccoud (2008), as análises sobre a desigualdade racial demonstram mudanças na sociedade brasileira, contudo, não permitem a visualização de alterações no tocante à mobilidade social dos negros. De acordo com a autora, examinando os dados da desigualdade social entre as décadas de 1940 a 1990, não é possível verificar uma variação na posição de brancos e negros na hierarquia social em razão do processo de crescimento e modernização econômica.

Não obstante as conquistas recentes alcançadas pelos movimentos sociais ligados à questão racial, notoriamente o cenário de desigualdades raciais persiste no 
país. Dados oficiais ${ }^{12}$ demonstram que uma enorme foço ainda separa brancos e negros de um acesso homogêneo ao mercado de trabalho e a educação pública superior. Existe uma assimétrica distribuição dos postos de trabalho e as remunerações salarias - mesmo quando ambos ocupam cargos semelhantes - são dispares.

Os dados do Radar Social (BRASIL, 2005) - publicado pelo IPEA - apontam que os programas focalizados nos indigentes, associados à estabilidade econômica e a alguma recuperação do poder de compra do salário mínimo, vêm tendo êxito na diminuição da indigência, mas sem alterar estruturalmente a pobreza e desigualdade. Entretanto, o referido estudo demonstra que $44,1 \%$ da população negra vive em domicílios com renda per capita familiar inferior a meio salário mínimo, índice que cai para 20,5\% entre os brancos. De acordo com Behring \& Boschetti (2008), esses dados confirmam que a estrutura da desigualdade brasileira tem cor.

Percebemos que no caso brasileiro as reivindicações feministas e raciais estão fundidas a um mercado de trabalho precário, acoplado a uma ampla margem de informalidade. A despeito de toda a polêmica e falta de consenso que permeia essa temática, presumimos que - para o alcance dessas aclamações - é necessária uma união entre esses setores e as bandeiras de luta das diferentes frações da classe trabalhadora.

Ao mesmo tempo, entendemos que a consolidação dessa fusão deve ser pautada numa abordagem crítica e dialética da realidade, que tenha como escopo a interlocução entre o universal e o particular e, portanto, reconheça tanto a perspectiva de classe como as especificidades de gênero e raça.

\footnotetext{
${ }^{12}$ Dados do Instituto de Pesquisa Econômica Aplicada (IPEA) revelam que dos 22 milhões de brasileiros que vivem abaixo da linha de pobreza extrema ou indigência, 70\% são negros. Além disso, entre os 53 milhões de pobres do país, $63 \%$ são negros.
} 
Após essa concisa apresentação das novas expressões da "questão social" dentro das particularidades históricas, culturais e sociais brasileiras, tentaremos estabelecer relações causais entre esse panorama - complexo e conflituoso - e o direito ao lazer. Trata-se, no entanto, de uma tarefa complexa, uma vez que não é uma relação bastante explorada pelo debate e produção acadêmico-científica brasileira.

Para além dos impactos ungidos pelas transformações econômicas, sociais e históricas expostas até o momento, o lazer é acometido por mutações internas relacionadas às propriedades e realidade do próprio fenômeno. Dentre as modificações presentes, destacaremos seu processo de mercadorização e padronização/uniformização.

A reestruturação capitalista e o atual padrão de acumulação de capital tendem a relegar todos os fenômenos da vida social à condição de mercadoria. Nesse contexto, o lazer não está imune ao processo de mercadorização. Ao contrário disso, a partir do reconhecimento - pela indústria do lazer e/ou do entretenimento - de seu elevado potencial econômico e fácil divulgação e aceitação, intensificou-se sua associação ao signo mercadológico, reduzindo-o a mero produto de relações comerciais.

Mascarenhas (2005) retrata bem o processo de mercadorização do lazer e sua respectiva abdicação aos antigos valores com os quais se vinculava. O referido autor cunhou o termo "mercolazer", referindo-se a expressão do lazer como mercadoria.

\footnotetext{
Se antes o lazer caracterizava-se como um antivalor ou uma antimercadoria, tratado como direito e alçado ao conjunto das políticas sociais como parte integrante da estratégia de financiamento público da reprodução da força de trabalho, além de incrementar a produtividade e preservar o salário para o consumo em massa de bens-duráveis, tal fenômeno assume agora uma posição muito mais de subordinação real do que de subordinação formal ao capital. Seus antigos atributos ou valores de uso sociais, dentre os quais podemos citar o descanso, a diversão ou o desenvolvimento, atrelados ou não a propósitos de cunho romântico, moralista, utilitarista ou compensatório, valem muito pouco no atual estágio de desenvolvimento do modo de produção capitalista. Em larga medida, cederam espaço ao mercolazer, do qual não se espera muito mais que a simples realização de um valor de troca, o salto perigoso em direção ao equivalente geral, momento final do giro do
} 
capital em que se resgata a mais-valia e se conferem os lucros, objetivo essencial e primeiro da indústria do lazer (MASCARENHAS, 2005, p. 106).

Segundo Mascarenhas (2005, p. 142), a afirmação do processo de mercadorização do lazer como o padrão hegemônico de compreensão e de apropriação desse fenômeno coincide com "o processo de mundialização da cultura, o que ocorre quando um conjunto de manifestações e expressões culturais, embora bastante diverso, passa a operar sobre uma base material, tecnológica e econômica comum, o mercado globalizado". Essa asseveração permite-nos avançar para a segunda metamorfose contemporânea do lazer, ou seja, sua padronização e/ou uniformização.

A globalização permitiu a criação de grandes conglomerados corporativos vinculados à pujante indústria do lazer e entretenimento por todo o mundo. Essa indústria utilizando, principalmente, dos mecanismos midiáticos encarregou-se de adentrar os lares e vender suas "fantasias". A ampliação desregrada de acesso a produtos e serviços comerciais pela internet possibilita que as pessoas naveguem pelo mundo sem sair de casa, comprando uma variedade de artigos em qualquer parte do globo terrestre, mesmo que esse não seja útil ou necessário. A internet e a televisão tornaram-se o paraíso da obsolescência programada e das falsas necessidades.

Por vezes, a uniformização é identificada como corolário principal do processo de globalização cultural. Todavia, a observação das mutações ocorridas no âmbito global da cultura permite verificar a presença do complexo e contraditório no interior destas transformações. Nesse sentido, a dinâmica de globalização cultural é capaz de produzir, simultaneamente, uniformidade e diversidade.

Contudo, o que temos assistido, recentemente, é a imposição de uma cultura hegemônica baseada nos valores dos países centrais, que promove a uniformização da realidade, sem um olhar diferenciado para as realidades locais. Dessa forma, cria-se o 
imaginário de um mundo homogêneo, no qual os sistemas de valores devem ser aqueles ditados por essa cultura predominante, que prega, por exemplo, a banalização e naturalização do consumismo desenfreado e das desigualdades sociais. Podemos aqui fazer um paralelo com as reflexões de Foucault (1982), ao identificar a migração da forma de ação do poder, que deixa de atuar na repressão direta e passa a agir como estimulador. Nessa nova atribuição age de forma a criar uma classe desesperada, ansiosa e consumista.

O fenômeno da globalização aliado à mercantilização do lazer homogeneizou e padronizou o acesso e a prática do lazer. Nesse quadro, resta-nos perguntar: E as velhas brincadeiras e jogos onde estão? Cadê os tradicionais eventos folclóricos e culturais? E a rua, não é mais espaço para a prática de lazer? A mercadorização reduziu a riqueza e diversidade cultural e regional das vivências do lazer ao quanto elas podem render em termos financeiros. A indústria cinematográfica é um exemplo emblemático da submissão de uma expressão cultural aos critérios mercadológicos. Filmes de boa qualidade, mas desprovidos de apelo mercantil, recebem a alcunha de "alternativos" e são retirados da grade horária das principais salas. Ao mesmo tempo, cinemas de bairro ou de rua, que poderiam abrigar os filmes menos comerciais, são extintos ou adquiridos por grandes corporações ${ }^{13}$.

Por falar na rua..., esta, primeiramente, foi estigmatizada e recebeu a pecha de local do risco e da vulnerabilidade social. Ao mesmo tempo, foi criminalizada e considerada o espaço do ócio e, portanto, propício para conduzir os jovens e adolescentes à criminalidade e drogadição. Diante desse cenário, seu abandono era

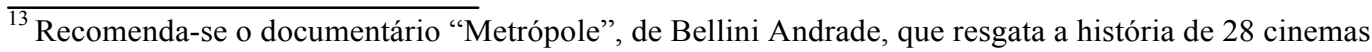
de rua de Belo Horizonte.
} 
previsível e estimulado. Aqueles que ainda resistem ou são deixados à própria sorte no ambiente urbano ou acabam sendo condenados a adjetivos pouco admiráveis e formam um contingente de "esquecidos entre os excluídos".

Portanto, nota-se que o processo de globalização acaba gerando cenários radicalmente paradoxos e antagônicos. Por um lado, professa aproximar os indivíduos, por outro lado, tem contribuído muito mais para o distanciamento e frigidez das pessoas. Declara ser um mecanismo de disseminação das mais diferentes culturas e capaz de proporcionar o enriquecimento cultural dos sujeitos, mas condena os países periféricos ao padrão cultural do mercado, imposto pelos países centrais.

Ao mercadorizar-se, o lazer ficou subsumido a esfera do consumo. Nessa condição, apenas aqueles afortunados e que podem compra-lo o acessarão. Dentro dessa perspectiva, é presumível que as classes subalternas tenham seu acesso ao direito do lazer ignorado ou resumido aos programas e projetos sociais governamentais. Dadas às especificidades anteriormente expostas, é possível que essa limitação seja sentida de forma mais intensa no âmbito da classe trabalhadora, sobretudo entre as mulheres e negros.

Dessa forma, é premente que o lazer seja reconhecido como direito social pelo Estado e que esse assuma sua responsabilidade de edificar uma política social pautada no acesso universal. Nesse sentido, devem-se evitar programas e projetos sociais fundados na ótica assistencial ou filantrópica. Além disso, políticas focais precisam reduzir-se a conjunturas e períodos onde elas sejam momentaneamente profícuas e necessárias. Esses são os desafios à consecução do lazer como direito diante das novas expressões da "questão social" e das desigualdades que compõe o contexto social histórico e cultural brasileiro. 


\section{Considerações Finais}

Debater e analisar a "questão social" é um desafio diante de toda a complexidade, dissenso e falta de homogeneidade que permeiam essa temática. A contraditoriedade que caracteriza esse fenômeno o acompanha da sua gênese até suas manifestações históricas (expressões) contemporâneas.

Diante dessa constatação, devemos evitar tomar as interpretações e análises deste texto como verdades peremptórias e irrefutáveis. Além disso, o sistema capitalista é um incessante ciclo de crises, que a cada abalo se reconfigura para ganhar sobrevida. Cada estratégia de sobrevivência adotada pelo capital impacta a organização da sociedade e cria novas necessidades e desafios à "questão social".

Os cuidados prescritos até o momento unem-se à dificuldade de problematizar temas polêmicos, na sociedade brasileira, como as questões de gênero e raciais. Outra árdua tarefa é a abordagem do lazer, uma vez que esse é um fenômeno multicultural, multidisciplinar e de infindáveis compreensões.

Ao introduzirmos o debate sobre o conceito de "questão social", demonstramos o caráter histórico dessa terminologia e sua vinculação à condição de pauperismo e a tomada de consciência da classe trabalhadora. Complementarmente, refutamos a possibilidade da existência de uma "nova questão social”, compreendendo que as mudanças atuais são expressões contemporâneas de uma contradição persistente entre as forças produtivas e as relações de produção do sistema capitalista.

Posteriormente, apresentamos nosso entendimento de que o lazer constitui um direito social, vinculado às lutas operárias pela redução da jornada de trabalho e conquista de acesso ao tempo livre. Por localizar-se entre os direitos sociais, 
defendemos que o lazer deve ser objeto de atenção do Estado a partir da implementação de políticas sociais e cariz universal.

$\mathrm{Na}$ sequência, expomos as novas expressões da "questão social" fruto das mudanças no mundo do trabalho e na dinâmica do sistema capitalista, buscando relaciona-las às singularidades sócio históricas e culturais presentes na sociedade contemporânea brasileira, sobretudo nas discussões de gênero e étnico-raciais. As apreciações demostraram que a condição de precarização trabalhista no Brasil é agravada para as mulheres e negros, os quais são submetidos a um mercado de trabalho composto por empregos subvalorizados.

Por fim, almejamos demonstrar que as limitações impostas pelas novas expressões da "questão social” e pelas desigualdades raciais e de gênero - no âmbito da política social de lazer - reúnem-se à mercantilização e homogeneização desse fenômeno. Tais procedimentos são engendrados pela lógica capitalista e pelo processo de globalização, e condicionam o acesso à prática do lazer à esfera do mercado. Esses limites comprovam a necessidade de que esse fenômeno cultural seja reconhecido como um direito social e, portanto, alvo de políticas sociais universalizantes empreendidas pelo Estado.

Finalizamos este texto, reafirmando a impossibilidade de uma conclusão definitiva e imutável, simultaneamente, ressaltamos a premência de estudos futuros que aprofundem as relações entre o direito ao lazer e a "questão social". Destarte, esperamos que essa pesquisa tenha sido uma primeira aproximação à temática e que seja assumida como incitação a pesquisas vindouras. 


\section{REFERÊNCIAS}

BAUMAN, Zygmunt. Vida a crédito. Rio de Janeiro: Zahar, 2010.

BEHRING, Elaine Rossetti. Acumulação capitalista, fundo público e Política Social. In: BOSCHETTI, Ivanete et al. (Org.). Política Social no capitalismo: tendências contemporâneas. 2. ed. São Paulo: Cortez, 2009.

BEHRING, Elaine R \& BOSCHETTI, Ivanete. Política Social: fundamentos e história. 5. ed. São Paulo: Cortez, 2008.

BOITO JR., Armando. A burguesia no Governo Lula. In: BASUALDO, Eduardo M.; ARCEO, Enrique. Neoliberalismo y sectores dominantes.Tendencias globales y experiencias nacionales. Buenos Aires, CLACSO, Consejo Latinoamericano de Ciencias Sociales. Ago. 2006. Disponível em: http://bibliotecavirtual.clacso.org.ar/ar/libros/grupos/basua/C07Boito.pdf. Acesso em: 1 abr. 2013.

BRASIL. Instituto de Pesquisa Econômica Aplicada (IPEA). Radar Social. Brasília, IPEA, 2005.

Presidência da República. Constituição da República Federativa do Brasil. Brasília: PR, 1988.

\section{. Senado Federal. Relatório da Comissão Externa da Feminização da Pobreza. Brasília, Senado Federal, 2004. Disponível em: http://www2.camara.leg.br/agencia/noticias/52962.html. Acesso em: 12 nov. 2012.}

CASTEL, Robert. As metamorfoses da questão social: uma crônica do salário. 8. ed. Petrópolis: Vozes, 2009.

FOUCAUlT, M. “Poder - corpo”. In: MACHADO, R. (Org.). Microfísica do Poder. Rio de Janeiro: Graal, 1982, p. 145-152.

GAMA, Andrea Sousa. As contribuições e os dilemas da crítica feminista para a análise do Estado de Bem-Estar Social. Brasília, Revista Ser Social, v. 10, n. 22, p. 41-68, 2008.

HÚNGARO, Edson Marcelo. Trabalho, tempo livre e emancipação humana: os determinantes ontológicos das políticas sociais de lazer. 2008. $264 \mathrm{f}$. Tese (Doutorado em Educação Física) - Faculdade de Educação Física, Universidade Estadual de Campinas, Campinas, 2008.

IAMAMOTO, Marilda. A questão social no capitalismo. In: Temporalis 3. Ano II. Rio de Janeiro: ABEPSS, 2001. 
JACCOUD, Luciana. Racismo e república: o debate sobre o branqueamento e a discriminação racial no Brasil. In: THEODORO, M. (Org.). As políticas públicas e a desigualdade racial no Brasil 120 anos após a abolição. Brasília: IPEA, 2008. 176 p.

LINHALES, M. A. A Trajetória Política do Esporte no Brasil: interesses envolvidos, setores excluídos. Belo Horizonte, 1996. 242f. Dissertação (Mestrado em Ciência Política) Faculdade de Filosofia e Ciências Humanas, UFMG, 1996.

MARX, K. "A Luta pela Jornada Normal de Trabalho... (3 itens relativos a essa questão). In: O Capital. v. 1. 3. ed. São Paulo: Ed. Nova Cultural, 1988. Col. Os Economistas

MASCARENHAS, Fernando. Entre o ócio e o negócio: teses acerca da anatomia do lazer. 2005. 308 f. Tese (Doutorado em Educação Física) - Faculdade de Educação Física, Universidade Estadual de Campinas, Campinas, 2005.

MÉSZÁROS, István. A crise estrutural do capital. São Paulo: Boitempo, 2009.

MISHRA, Ramesh. Marx e o Bem Estar, 1975. (original: Marx and Welfare State, in Sociological Review, New Series, v. 23, n. 2, 1975.

MONTAÑO, Carlos. Terceiro setor e a questão social: crítica ao padrão emergente de intervenção social. São Paulo: Editora Cortez, 2002.

.; DURIGUETTO, Maria L. Estado, classe e movimento social. São Paulo: Cortez, 2010.

NETTO, José Paulo. Transformações societárias e Serviço Social - notas para uma análise prospectiva da profissão no Brasil. Serviço Social \& Sociedade, São Paulo, v. 17, n. 50, Cortez, p. 87-132, 1996.

. Cinco notas a propósito da "questão social". Temporalis 3. Ano II. Rio de Janeiro: ABEPSS. Janeiro a junho de 2001.

PEREIRA, Potyara A. P. Questão social, Serviço Social e direitos de cidadania. In: Temporalis 3. Ano II. Rio de Janeiro: ABEPSS, 2001.

Discussões conceituais sobre política social como política pública e direito de cidadania. In: BOSCHETTI, I.; et al. Política social no capitalismo: tendências contemporâneas. São Paulo: Cortez, 2008. p. 87-108.

ROSANVALLON, Pierre. A nova questão social: representando o Estado providência. Brasília: Instituto Teotônio Vilela, 1998. 
SEP (Sociedade Brasileira de Economia Política). Fundamentos sociais das economias pós-industriais: uma resenha crítica de Gosta Esping-Andersen. Área IV - 09: Economia, Mercado e Instituições. In: ENCONTRO NACIONAL DE ECONOMIA POLÍTICA, n. 9, 2004, Uberlândia. Anais... Disponível em: http://www.sep.org.br/pt/artigo old list.php?id=9\&ar_nome=\&page=2.

TELLES, Vera da Silva. Direitos sociais: afinal do que se trata? Belo Horizonte: Editora UFMG, 1999.

UNESCO. Declaração Universal dos Direitos Humanos. 1948.

\section{Endereço do Autor:}

Pedro Fernando A. Athayde

SHIS QI 9, Conjunto 7, Casa 7 - Lago Sul

Brasília/DF - CEP: 71625-070

Endereço Eletrônico: pedroavalone@gmail.com 